\title{
Temperature and Humidity Control System Model using Arduino Nano
}

\author{
Yoice R. Putung \\ Department of Electrical \\ Engineering \\ Manado State Polytechnic \\ Manado, Indonesia
}

\author{
Herry S. Langi \\ Department of Electrical \\ Engineering \\ Manado State Polytechnic \\ Manado, Indonesia
}

\author{
Sonny R. Kasenda \\ Department of Electrical \\ Engineering \\ Manado State Polytechnic \\ Manado, Indonesia
}

\author{
Josephin Sundah \\ Department of Electrical Engineering \\ Manado State Polytechnic \\ Manado, Indonesia
}

\begin{abstract}
The aim of this research is to get a model of room temperature and humidity control system using web-based Arduino nano using temperature and humidity sensors (DHT11 sensor) to measure temperature and humidity in a room.

Buzzer will work when the temperature is above 30 degrees, the led is used to indicate conditions, the green led for temperatures below 30 degrees and the red led for temperatures above 30 degrees. The fan is installed in the room and will work (on) if the temperature is above 30 degrees. To display web-based data, NodeMCU ESP8266 v.3 is used which can send sensor data to the web.
\end{abstract}

\section{Keywords}

Temperature, humidity, web, arduino

\section{INTRODUCTION}

Smart Building is the technology of choice that is able to simulate real conditions to be computerized, making it easier to manage or monitor a situation in a building that has a lot of space. Physical computing is a concept to understand the human relationship between environments that are analogous to the digital world [1].

This research aims to design a web-based temperature and humidity monitoring system model using Arduino to monitor room conditions using the internet network. The problem is limited to web design and displays the values of temperature and humidity. The hardware used is Arduino nano, NodeMCU ESP8266 v.3, DHT11 sensor (temperature and humidity). While the software used is Arduino version 1.0.7 for programming the Arduino Uno and javascript, XAMPP microcontrollers which contain Apache, PHP and Mysql modules.

\section{LITERATURE REVIEW}

Monitoring will provides status information and trends that measurement and repeated evaluations of time to time, monitoring generally done for a specific purpose, for check against the following process object or to evaluate conditions or progress towards management outcome objectives over the effects of actions of some kind among other things, actions for maintain moderate management running[2]

Buzzer is an electronic component that functions to convert electric vibrations into sound vibrations.

DHT11 is a Temperature \& Humidity sensor that has a calibrated digital signal output. Using Digital Signal Acqusition technique and temperature and humidity sensing technology, this sensor has high reliability and good long term stability. This sensor includes a resistive humidity measurement component and an NTC temperature measurement component connected to an 8-bit microcontroller so that it offers good quality, fast response and anti-interference capabilities [3].

The DHT11 sensor is a sensor that can measure two environmental parameters at once, namely temperature and humidity. In this sensor there is an NTC (Negative Temperature Coefficient) thermistor for measuring temperature, a resistant type humidity sensor and an 8-bit microcontroller that processes the two sensors and sends the results to the output pins in a single-wire bi-directional format (single cable. two-way direction). The sensor has 4 pins, with a PCB breakout that has 3 pins as fig 1 .

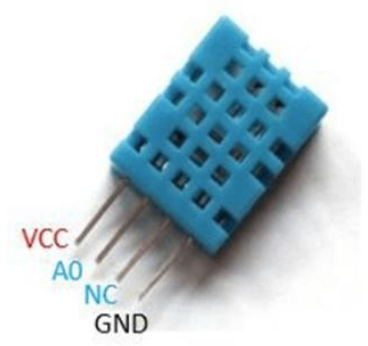

Without Breakout PCB

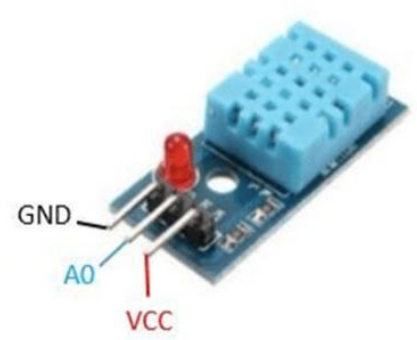

With Breakout PCB
Fig 1. DHT11 sensor

NodeMCU is a development of the ESP 8266 with e-Lua based firmware. NodeMcu is equipped with a micro usb port that functions for monitoring and power supply. In addition, NodeMCU is equipped with a reset and flash button. NodeMCU uses the Lua programming language which is a package of esp8266[4,5]. 


\section{RESULTS OF ANALYSIS COMPONENTS AND DISCUSSION}

As for the description of the model developed can be seen in Figure 2. After reading the data from the DHT11 sensor, the data from the sensor will go to serial and the sensor data will also be displayed on the LCD. If temperature $>=30$, the red light will turn on, the green light will be off, the buzzer will be active. If the temperature is not $>=30(<30)$, the red light will be off, the green light will be on. If tssehe switch is on, the buzzer will be active, while if the switch is off the buzzer will turn off. ESP8266 must be connected to wifi, then read the DHT11 sensor data from the serial then send data from the DHT11 sensor to the web server with the GET URL. Open port 80 and wait for the get request. If there is a request it will retrieve DHT11 sensor data from the GET URL then update the chart / web. If there is no request it will be lopping back waiting for the get request. Figure 3 . In this figure, the proposed model for monitoring temperature and humidity.

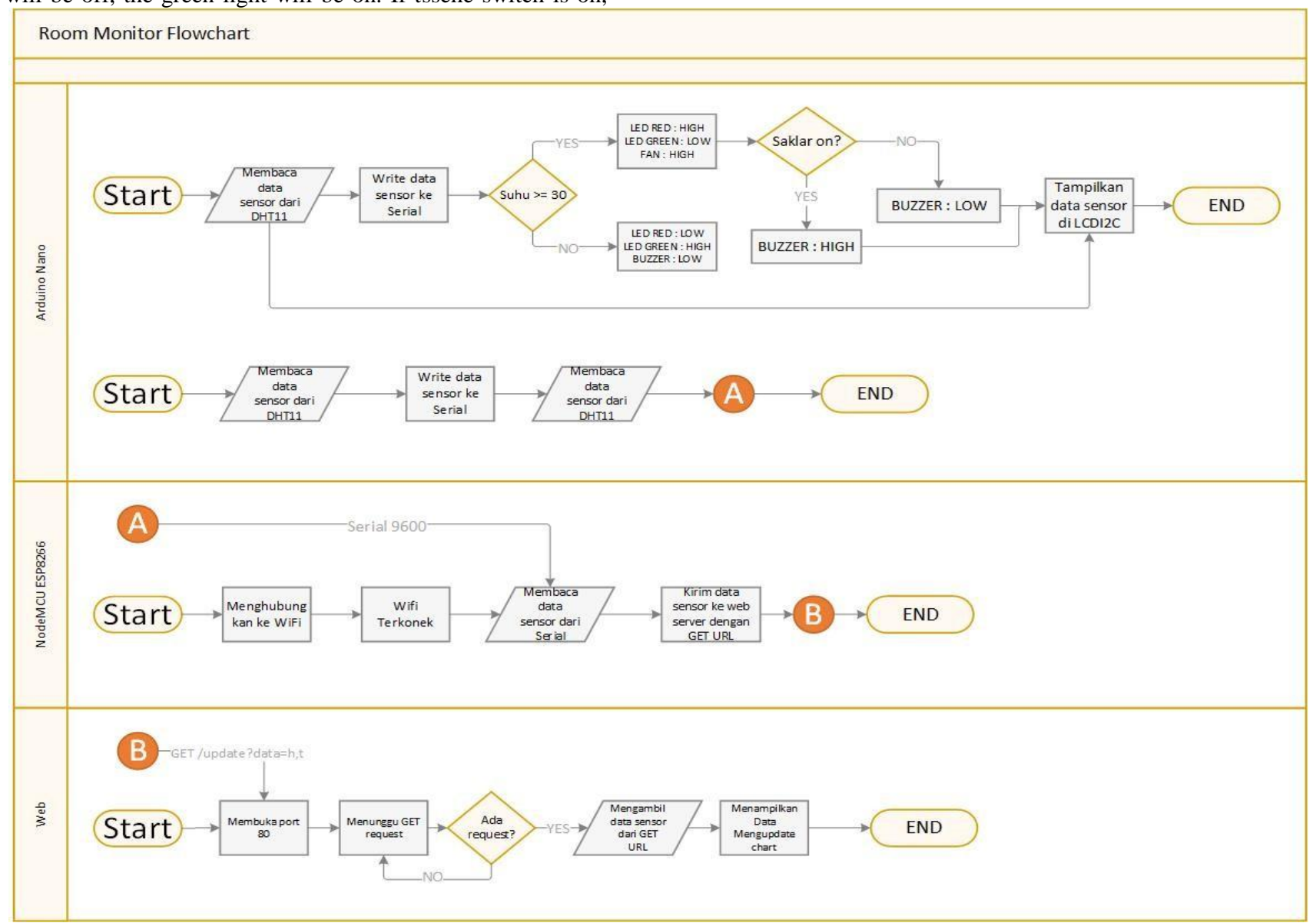

Fig 2. System Flowchart

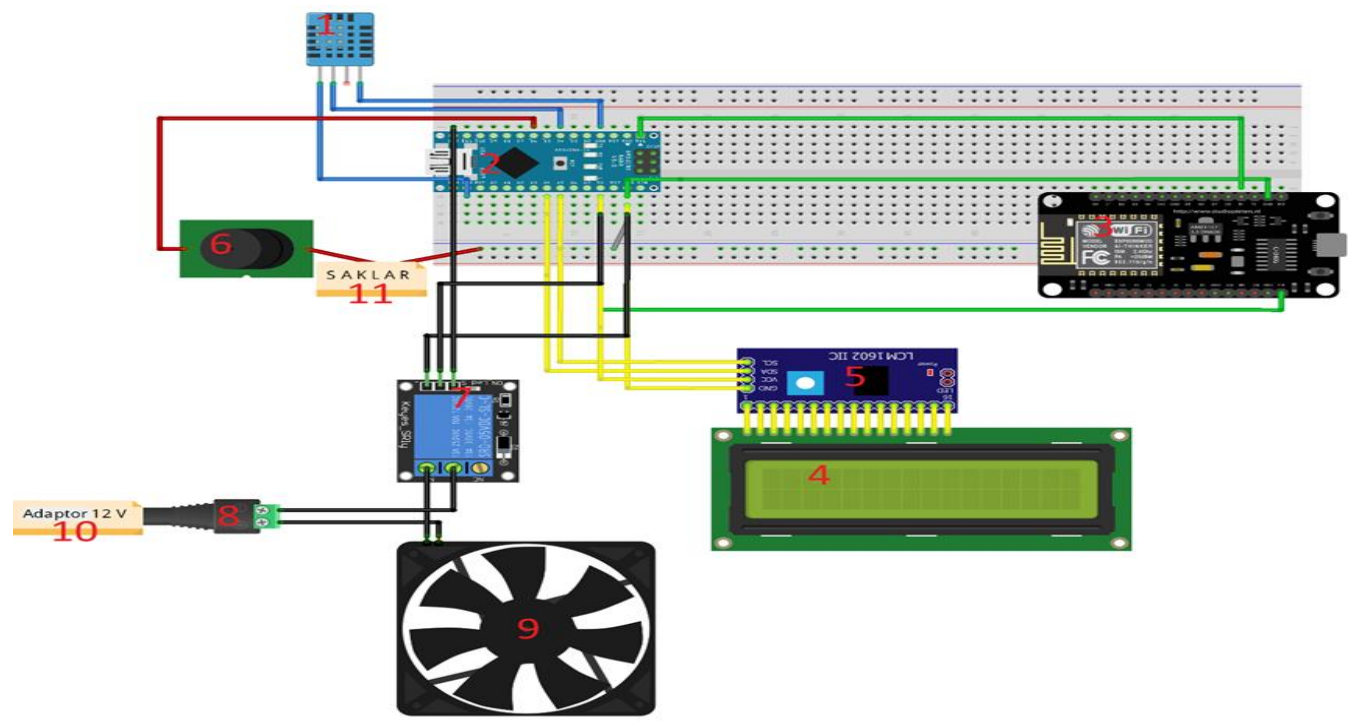

Fig 3. Monitoring system model 
Data read by the sensor will be sent to a web page making monitoring easier. as for the results obtained are :

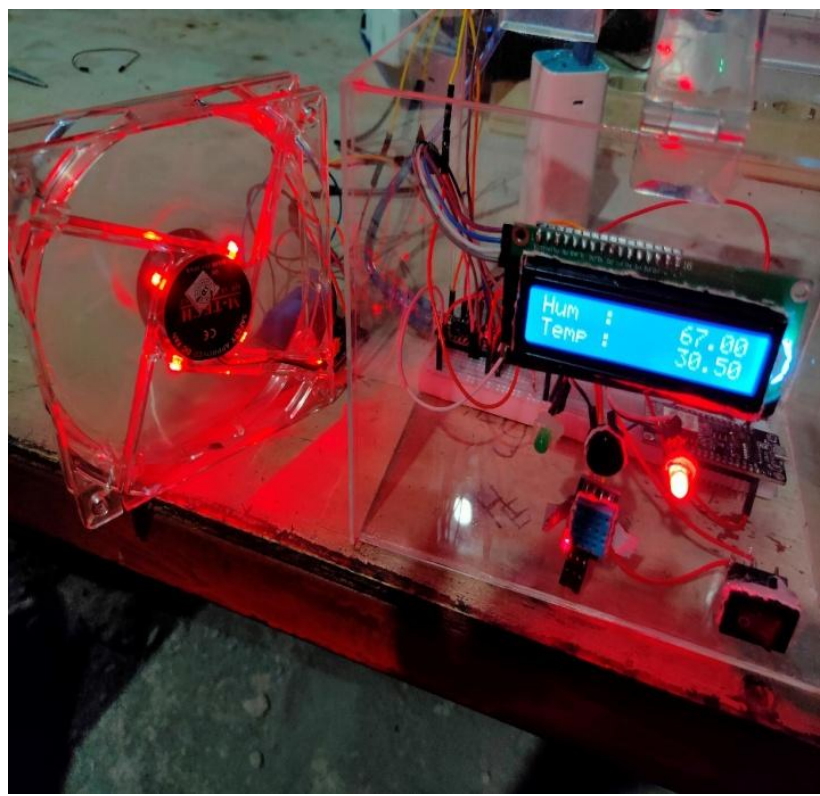

Fig 4. The temperature state is above 30
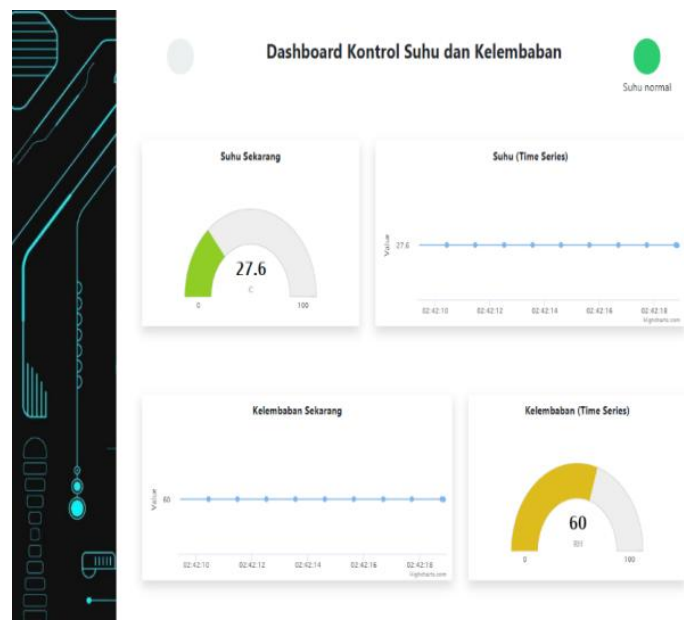

Fig 5. Web display

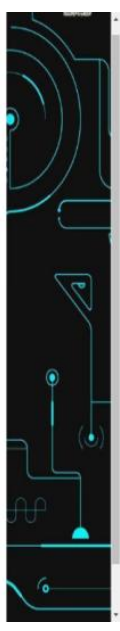

To display the measurement data on the $\mathrm{LCD}$, the program code is :

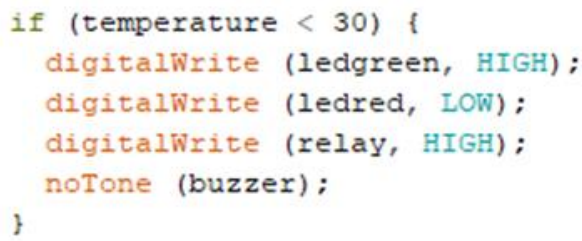

If the temperature is below 30 degrees the green light will turn on, the red light will turn off, the buzzer will not sound, and the relay turns off and the fan offf. otherwise if the temperature is more than equal to 30 , the green light will turn off, the red light will light up, the buzzer will sound, the relay will turn on and the fan will spin [6].

\section{CONCLUSION}

From the test results, the temperature and humidity monitoring system designed using DHT11, Arduino Nano, and NodeMCU sensors can display monitoring data with realtime web output. If temperature $>=30$, the red light will turn on, the green light will be off, the buzzer will be active. If the temperature is not $>=30$, the red light will be off, the green light will be on.

\section{REFERENCES}

[1] Mandarani, P. (2014). Perancangan Dan Implementasi User Interface Berbasis Web Untuk Monitoring Suhu, Kelembaban Dan Asap Pada Ruangan Berbeda Dengan Memanfaatkan Jaringan Local Area Network. Jurnal Teknoif, 2(2) .

[2] Malik, Shadan. 2005. Enterprise Dashboards - Design and Best Practices for IT. John Wiley \& Sons, Inc

[3] Micro4you . DHT11 Humidity \& Temperature Sensor <URL: www.micro4you.com/files/sensor/DHT11.pdf >

[4] R.A.Ramlee, M.H.Leong, R.S.S. Singh, M.M.Ismail, M.A.Othman,H.A.Sulaiman, M.H.Misran, M.A.Meor Said, Bluetooth Remote Home Automation System Using Android Application, The International Journal of Engineering And Science (IJES), Issue 01, Volume 2, pp.149-153, 2013.

[5] Rahmawati, V. 2017. NodemCu. Animal Genetics

[6] Sawidin, S., Pongoh, D. S., \& Ramschie, A. A. System Design Temperature and Humidity Control Room with Android. International Journal of Computer Applications, $975,8887$. 